\title{
Synergistic induction of apoptosis by mapatumumab and anthracyclines in human bladder cancer cells
}

\author{
SYED MINHAJ UDDIN AHMED ${ }^{1 *}$, XIUXIAN WU ${ }^{1,2^{*}}$, XINGHUA JIN $^{2,3}$, XIA ZHANG $^{1}$, YOSHIKAZU TOGO ${ }^{2}$, \\ TORU SUZUKI ${ }^{2}$, YONGNAN LI ${ }^{2,4}$, AKIHIRO KANEMATSU ${ }^{2}$, MIKIO NOJIMA ${ }^{2}$, \\ SHINGO YAMAMOTO $^{2}$, MIKIO SUGIMOTO ${ }^{1}$ and YOSHIYUKI KAKEHI $^{1}$ \\ ${ }^{1}$ Department of Urology, Faculty of Medicine, Kagawa University, Kita-gun, Kagawa 761-0793; ${ }^{2}$ Department of Urology, \\ Hyogo Medical College, Nishinomiya City, Hyogo 663-8501, Japan; ${ }^{3}$ Qiqihar Medical University, Jianhua, Qiqihar, \\ Heilongjiang 161006; ${ }^{4}$ Mudanjiang Medical University, Aimin, Mudanjiang, Heilongjiang 157011, P.R. China
}

Received October 24, 2014; Accepted November 21, 2014

DOI: 10.3892/or.2014.3654

\begin{abstract}
Tumor necrosis factor-related apoptosis-inducing ligand (TRAIL) triggers apoptosis in a variety of tumor cells by engaging the death receptors 4 (DR4) and 5 (DR5). We investigated the effect of chemotherapeutic drugs on DR4-mediated apoptosis in human bladder cancer cells, using a human monoclonal agonistic antibody specific for DR4, mapatumumab. Cytotoxicity was determined by 3-(4,5-dimethylthiazol-2-yl)2,5-diphenyltetrazolium bromide assay. Synergy was assessed by isobolographic analysis. Treatment of human bladder cancer T24 cells with mapatumumab in combination with mitomycin C, vinblastine or gemcitabine did not overcome resistance to these agents. However, treatment with mapatumumab in combination with epirubicin (EPI) had a synergistic cytotoxic effect. Synergy was also obtained in KU7 and RT112 human bladder cancer cells. A synergistic effect was also observed with mapatumumab in combination with pirarubicin. The synergy obtained in cytotoxicity with mapatumumab and EPI was also achieved in apoptosis. EPI markedly increased DR4 expression in the bladder cancer cells at both the mRNA and protein levels. Furthermore, the combination-induced cytotoxicity was significantly suppressed by the DR4:Fc chimeric protein. The combination of EPI and mapatumumab significantly activated the caspase cascade, including caspase-8, -9 and -3 , which are the downstream molecules of death receptors. These findings indicate that EPI sensitizes bladder cancer cells to DR4-mediated apoptosis through
\end{abstract}

Correspondence to: Professor Yoshiyuki Kakehi, Department of Urology, Faculty of Medicine, Kagawa University, 1750-1 Miki-cho, Kita-gun, Kagawa 761-0793, Japan

E-mail: kakehi@med.kagawa-u.ac.jp

Dr Xiuxian Wu, Department of Urology, Hyogo Medical College, 1-1 Mukogawa-cho, Nishinomiya City, Hyogo 663-8501, Japan E-mail:wuxian@hyo-med.ac.jp

${ }^{*}$ Contributed equally

Key words: DR4, apoptosis, bladder cancer cells, mapatumumab, anthracyclines induction of DR4 and activation of caspases, suggesting that the combination therapy of EPI and mapatumumab may be effective for bladder cancer therapy.

\section{Introduction}

Each year more than 350,000 new cases of bladder cancer are diagnosed globally (1), making bladder cancer the ninth most frequent cancer worldwide (2). Epirubicin (EPI) and pirarubicin (THP) are a new generation of anthracycline drugs, widely used as anticancer chemotherapeutic agents in various types of cancers including bladder cancer $(2,3)$. Furthermore, these anthracycline drugs are less cardiotoxic than doxorubicin. However intrinsic and acquired resistance to chemotherapeutic drugs are considered as major problems. Therefore, it is important to develop new treatment strategies for bladder cancer patients to prevent recurrence and reduce the risk of tumor progression.

Tumor necrosis factor (TNF)-related apoptosis-inducing ligand (TRAIL) is a pro-apoptotic member of the TNF superfamily and a potentially effective anticancer agent. TRAIL has been identified as a powerful activator of programmed cell death or apoptosis in various tumor cells, yet is considered relatively nontoxic against most normal cells (4-6). TRAIL induces apoptosis by interacting with two death-inducing receptors TRAIL-R1 (DR4) and TRAIL-R2 (DR5) following activation of the caspase cascade that initiates both extrinsic and intrinsic apoptotic pathways (4,7-9). In addition, TRAIL binds to two other receptors, TRAIL-R3 (DcR1) and TRAIL-R4 (DcR2), which lack a functional cytoplasmic death domain (8-10). These receptors have been proposed to inhibit TRAIL-induced apoptosis by acting as decoy receptors. Thus, using a specific activator of TRAIL-R1 and TRAIL-R2 is preferable to avoid interference from competition with decoy receptors.

It has been reported that monoclonal antibodies (mAbs) to human TRAIL-R1 or TRAIL-R2 have antitumor activities in vitro and in vivo $(11,12)$. These agonistic antibodies work in a similar manner to TRAIL by activating TRAIL-mediated apoptotic pathways $(12,13)$. Several studies have shown that the human TRAIL-R1 mAb induced apoptotic cell death in renal cell carcinoma (RCC) $(14,15)$ and bladder cancer cells (16). 
It has also been reported that mapatumumab which is a fully human agonistic mAb specific for TRAIL-R1, reduced the viability of multiple types of tumor cells in vitro and inhibited tumor growth in vivo (17).

The results of phase I and II studies with mapatumumab showed good compatibility and only mild non-specific toxicity in patients with solid malignancies $(18,19)$. Although these clinical trials are promising, it was recognized that only $29.3 \%$ of patients had stable disease among the patients who received mapatumumab therapy (20). Therefore, developing strategies to optimize the effects of mapatumumab, particularly through combinations with chemotheraputic drugs, is warranted.

In the present study, we examined whether the cytotoxic effect of mapatumumab would be enhanced in combination with chemotherapeutic drugs against bladder cancer cells. The subtoxic concentrations of the EPI and mapatumumab combinations exhibited synergistic cytotoxicity and induction of apoptosis through upregulation of DR4.

\section{Materials and methods}

Reagents and cell lines. Mapatumumab, the human TRAIL-R1 $\mathrm{mAb}$, was kindly provided by Human Genome Sciences (Rockville, MD, USA). This monoclonal antibody was isolated using phage display technology (21). Enzyme-linked immunosorbent assay (ELISA) and/or Biacore analysis determined that mapatumumab is highly specific for binding to TRAIL-R1. EPI and THP were obtained from Meiji Pharmaceutical and Kyowa Hakkou (Tokyo, Japan), respectively.

The human bladder carcinoma cells T24, KU7, RT112, 253J and J82 were purchased from the American Type Culture Collection (ATCC; Manassas, VA, USA). Cells were cultured in RPMI-1640 medium supplemented with $1 \mathrm{mM}$ HEPES buffer (both from Sigma, St. Louis, MO, USA), penicillin and streptomycin mixture (Nakalai, Kyoto, Japan) and 10\% heat-inactivated fetal bovine serum (Sigma).

Cytotoxicity assay. Cytotoxicity was assessed using a 3-(4,5-dimethythiazol-2-yl)-2,5-diphenyltetrazolium bromide (MTT) assay. A $100 \mu \mathrm{l}$ suspension of $1.5 \times 10^{4}$ cells was seeded into a 96-well flat-bottom microtiter plate. Cells were grown for $24 \mathrm{~h}$ at $37^{\circ} \mathrm{C}$ in a humidified $5 \% \mathrm{CO}_{2}$ atmospheric condition, after which cells were exposed to $100 \mu \mathrm{l}$ of drug solution or medium (control) to the plates in triplicate. Each plate was incubated for $24 \mathrm{~h}$. Following incubation, $10 \mu \mathrm{l}$ MTT labeling reagent (Roche, Mannheim, Germany) was added to each culture well, and the cultures were incubated for an additional $4 \mathrm{~h}$. After incubation, $100 \mu \mathrm{l}$ solubilization solution containing $10 \% \mathrm{SDS}$ in $0.01 \mathrm{M} \mathrm{HCl}$ was placed into each well and incubated overnight. The absorbance (A) of each well was measured by a microculture plate reader at $540 \mathrm{~nm}$. Percent cytotoxicity was calculated by the following equation: Cytotoxicity $=[1-(\mathrm{A}$ of experimental wells/A of control wells)] x 100 .

Apoptosis assay. Following incubation with mapatumumab and/or EPI for 6-24 h, both floating and adherent cells were harvested. A cell death detection ELISA kit (Roche) was used to assess quantification of DNA fragmentation according to the manufacturer's instructions. The harvested cells were mixed thoroughly with $200 \mu \mathrm{l}$ cell lysis buffer and kept in ice for $30 \mathrm{~min}$. Subsequently, centrifugation at 1,500 rpm for $10 \mathrm{~min}$ was carried out. Using the Bio-Rad DC protein assay (BioRad, Hercules, CA, USA), the protein concentration of the supernatant was measured, and $20 \mu \mathrm{l}$ cell lysate corresponding to $50 \mu \mathrm{g}$ protein was transferred into a streptavidin-coated microplate, $80 \mu \mathrm{l}$ immunoreagent was added to each well and incubation for $2 \mathrm{~h}$ at room temperature was carried out. After removing the immunoreagent and washing with incubation buffer, $100 \mu \mathrm{l}$ ABTS solution and ABTS stop solution were added accordingly, and the $\mathrm{A}$ at $405 \mathrm{~nm}$ was measured.

Real-time reverse transcription-PCR. The mRNA expression of DR4 was examined by reverse transcriptase-polymerase chain reaction (RT-PCR) analysis. Total RNA was extracted from the bladder carcinoma cells using TRIzol (Life technologies, Carlsbad, CA, USA) according to the manufacturer's instructions, and complementary DNA (cDNA) was synthesized from $1 \mu \mathrm{g}$ of the total RNA with the First-Strand cDNA Synthesis kit (Applied Biosystems, Foster City, CA, USA). The primer set for DR4 (Sigma) was as follows: forward, 5'-CGA TGTGGTCAGAGCTGGTACAGC and reverse, 5'-GGACAC GGCAGAGCCTGTGCCATC. The real-time RT-PCR was carried out using LightCycler FastStart DNA Master SYBRGreen 1 (Roche). The protocol applied for TRAIL-R1 was 40 cycles at $95^{\circ} \mathrm{C}$ for $10 \mathrm{sec}, 63^{\circ} \mathrm{C}$ for $1 \mathrm{sec}$, and $72^{\circ} \mathrm{C}$ for $4 \mathrm{sec}$. Quantitative analysis of the data was carried out using LightCycler Software version 3.5 (Roche). Standard curves for templates of TRAIL-R1 and glyceraldehyde-3-phosphate dehydrogenase were generated by serial dilution of the PCR products.

Western blot analysis. The protein expression of DR4 was examined by western blot analysis. Cells were plated in $100-\mathrm{mm}$ dishes for $24 \mathrm{~h}$ and then treated with the combination of mapatumumab $(100 \mathrm{ng} / \mathrm{ml})$ and EPI $(1 \mu \mathrm{g} / \mathrm{ml})$ for $3-12 \mathrm{~h}$ in a cell culture incubator at $37^{\circ} \mathrm{C}$. After the indicated treatment, the cells were lysed for $30 \mathrm{~min}$ on ice in lysis buffer with protease inhibitor cocktail (Sigma). The protein concentration of the extracts was determined by Bio-Rad colorimetric assay. Then $50 \mu \mathrm{g}$ of protein was separated on an SDS-PAGE and transferred to a PVDF membrane (GE Healthcare Life Sciences, Buckinghamshire, UK). After blocking the nonspecific binding sites for $1 \mathrm{~h}$ at room temperature with $5 \%$ skim milk in TBST (TBS with $0.1 \%$ Tween-20), the membranes were incubated overnight at $4^{\circ} \mathrm{C}$ with primary antibodies: DR4 mouse monoclonal antibody (Santa Cruz Biotechnology, Inc., Dallas, TX, USA) and $\beta$-actin rabbit polyclonal antibody (Cell Signaling Technology, USA). The membranes were then washed 3 times with TBST and incubated further at room temperature for $1 \mathrm{~h}$ with the respective secondary antibodies. Membranes were washed 3 times with TBST and signals were detected using West Pico Chemiluminescent Substrate kit (Thermo Scientific).

Caspase activity assay. The activities of caspase- $3,-8$ and -9 were measured using a quantitative colorimetric assay with caspase-3, -8 and -9 colorimetric protease assay kits (MBL, Nagoya, Japan). Control and treated cells (6-12 h) were homogenized in $400 \mu \mathrm{l}$ cell lysis buffer, incubated on ice for 
A

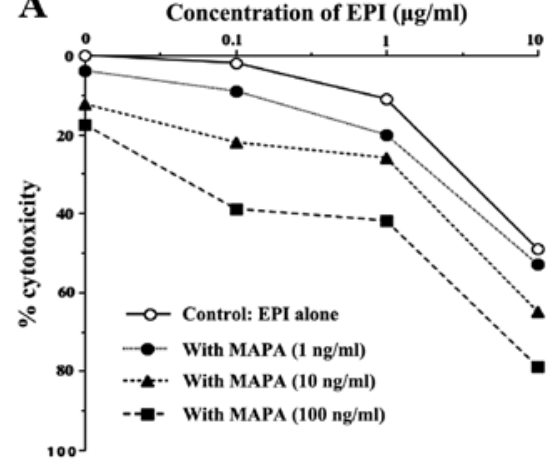

C

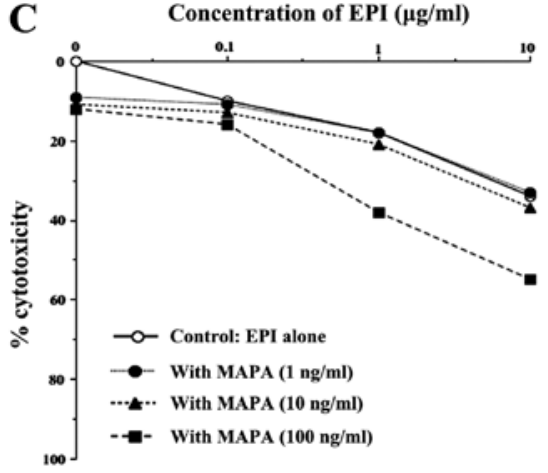

E

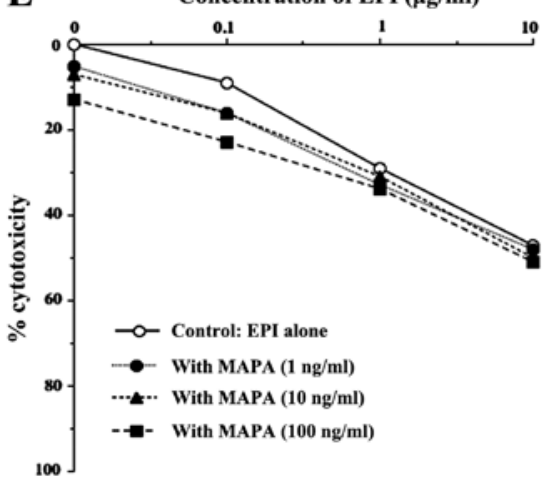

B

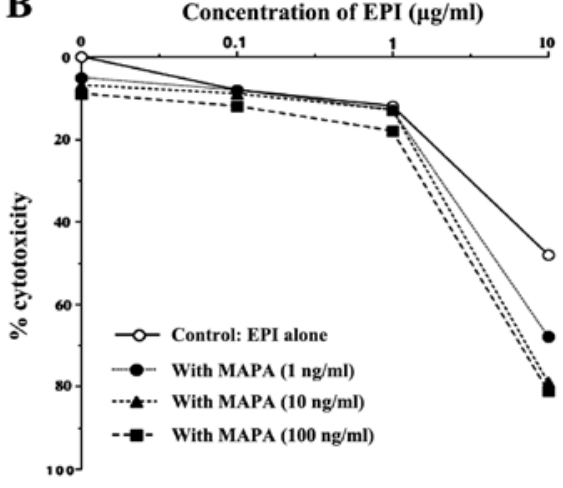

D

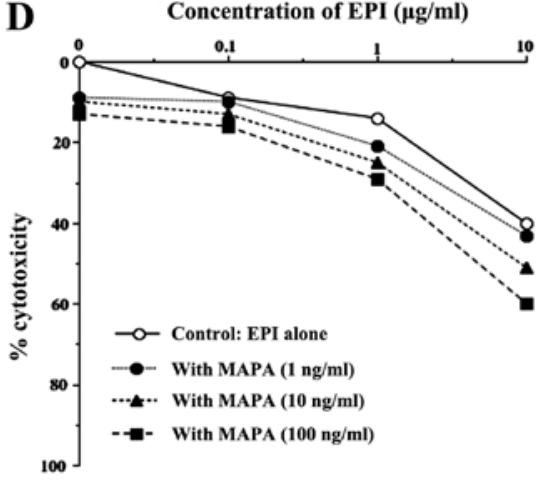

F

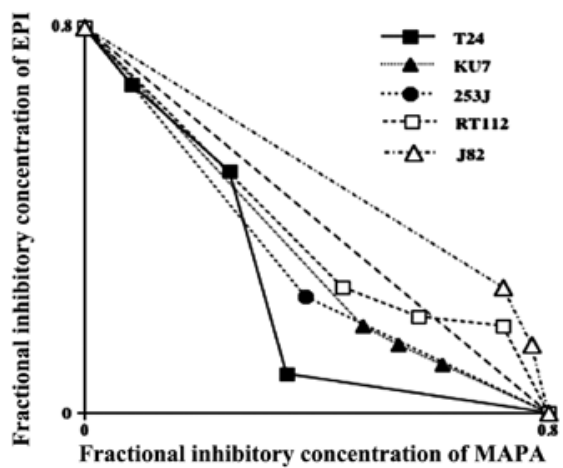

Figure 1. Combined cytotoxicity of MAPA and EPI on bladder cancer (A) T24, (B) KU7, (C) 253J, (D) RT112 and (E) J82 cells. Cells were treated for 24 h with MAPA (1-100 ng/ml) alone, EPI (0.1-10 $\mu \mathrm{g} / \mathrm{ml})$ alone or the combination of the two agents. Cytotoxicity was measured using the MTT assay. (F) Combined effects on the 5 types of bladder cells were assessed by isobolograpic analysis. MAPA, mapatumumab; EPI, epirubicin.

$10 \mathrm{~min}$ and centrifuged at $10,000 \mathrm{rpm}$ for $5 \mathrm{~min}$ at $4^{\circ} \mathrm{C}$. The supernatant was recovered and the protein concentration was measured with the Bio-Rad DC protein assay. Then $50 \mu \mathrm{l}$ cell lysate corresponding to $100 \mu \mathrm{g}$ of total protein, $50 \mu \mathrm{l}$ of $2 \mathrm{X}$ reaction buffer containing $10 \mathrm{nM}$ DTT and $5 \mu l$ substrate were added to each well of a 96-well plate. The plate was incubated for $24 \mathrm{~h}$ at $37^{\circ} \mathrm{C}$. The A value of each well was measured with a microculture plate reader at $405 \mathrm{~nm}$.

Statistical analysis. All measurements were conducted 3 times. The results are expressed as the means \pm SD of 3 experiments. Statistical significance was determined by the Student's t-test with P-value. A P-value of $<0.05$ was considered to indicate a statistically significant result.

Calculations of synergistic cytotoxicity were determined by isobolograpic analysis as described by Berenbaum $(22,23)$. Whether any particular dose combination is synergistic, addi- tive or antagonistic is shown by whether the point representing that combination lies below, on or above, respectively, the straight line joining the doses of two drugs that, when given alone, produce the same effect as that combination in the isobolographic analysis.

\section{Results}

Cytotoxicity of a combination of mapatumumab and EPI on bladder cancer cells. We examined whether the cytotoxic effect of mapatumumab on bladder cancer cells would be enhanced by a combination with EPI, mitomycin C, vinblastine or gemcitabine. When T24 cells were treated with a combination of mapatumumab (1-100 ng/ml) and subtoxic concentrations of EPI $(0.1-10 \mu \mathrm{g} / \mathrm{ml})$ for $24 \mathrm{~h}$, a significant potentiation of cytotoxicity and synergy was achieved (Fig. 1A and F), although there was no synergistic effect of mapatumumab in combination 

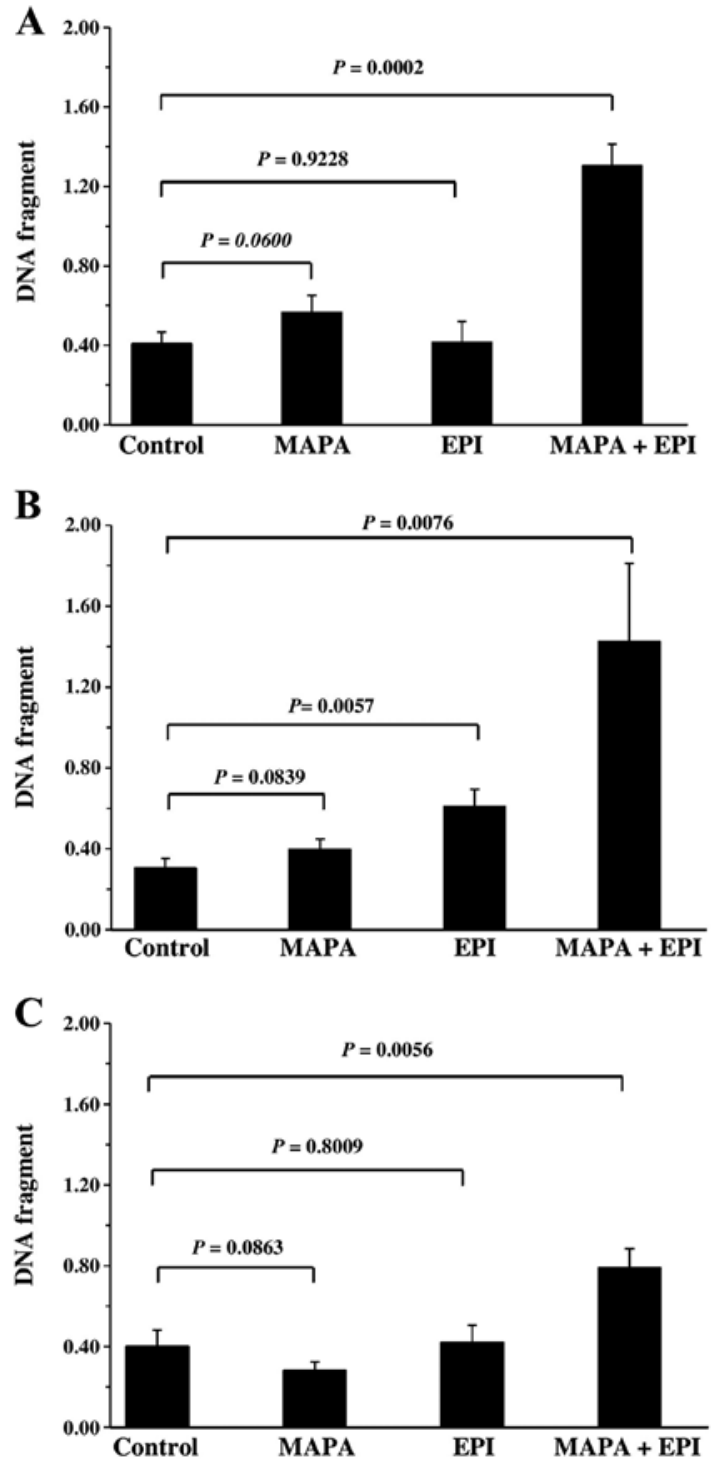

Figure 2. Induction of apoptosis by the combination of MAPA and EPI in bladder cancer cells. (A) T24, (B) 253J and (C) J82 cells were treated for $12 \mathrm{~h}$ with MAPA $(100 \mathrm{ng} / \mathrm{ml})$ alone, EPI $(1 \mu \mathrm{g} / \mathrm{ml})$ alone or a combination of the two agents. Quantification of DNA fragmentation was assessed using the apoptosis-specific ELISA assay. MAPA, mapatumumab; EPI, epirubicin.

with mitomycin $\mathrm{C}$, vinblastine or gemcitabine $(0.1-10 \mu \mathrm{g} / \mathrm{ml}$; data not shown). A similar synergistic effect was also achieved in the KU7 (Fig. 1B and F) and 253J cells (Fig. 1C and F). The synergistic effect was also observed with mapatumumab in combination with THP (data not shown). In addition, an additive effect was observed in the RT112 cells (Fig. 1D and F). On the other hand, an antagonize effect was achieved in the J82 cells (Fig. 1E and F). These studies showed that treatment of most human bladder cancer cells with a combination of mapatumumab and EPI/THP resulted in the potentiation of cytotoxicity.

Induction of apoptosis. We assessed whether the enhanced cytotoxicity of mapatumumab and EPI combination was mediated through apoptosis. When mapatumumab and EPI were used alone neither mapatumumab nor EPI caused DNA fragmentation. However, obvious DNA fragmentation was
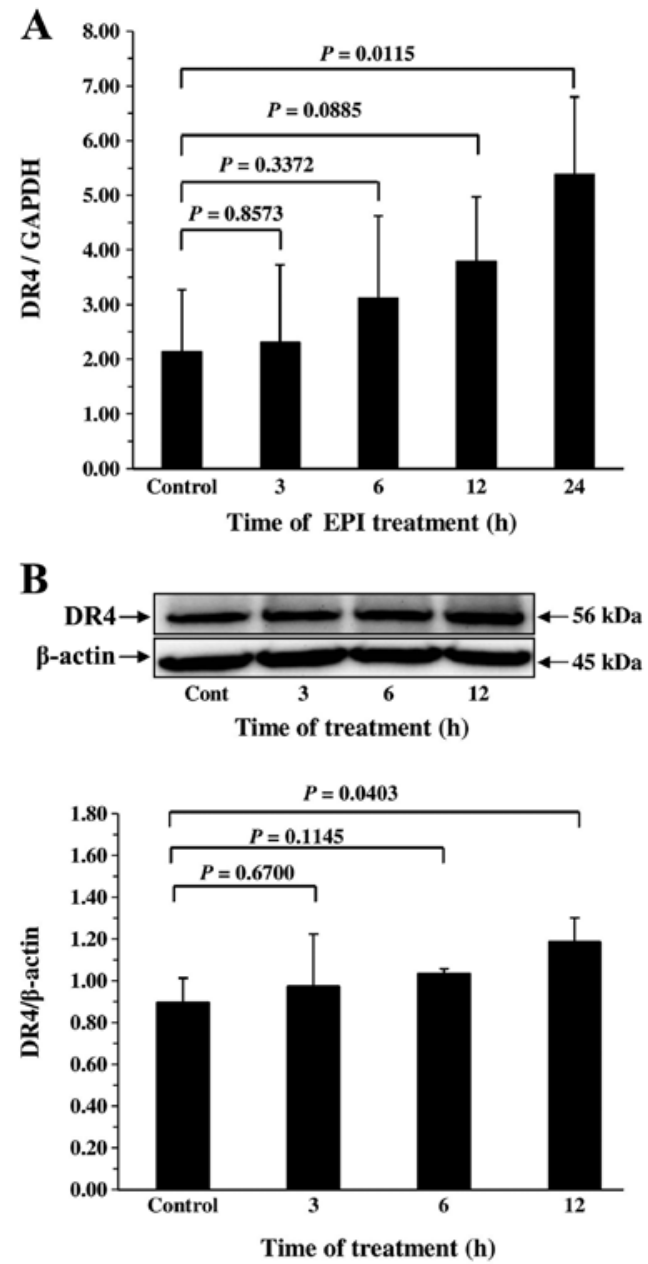

C

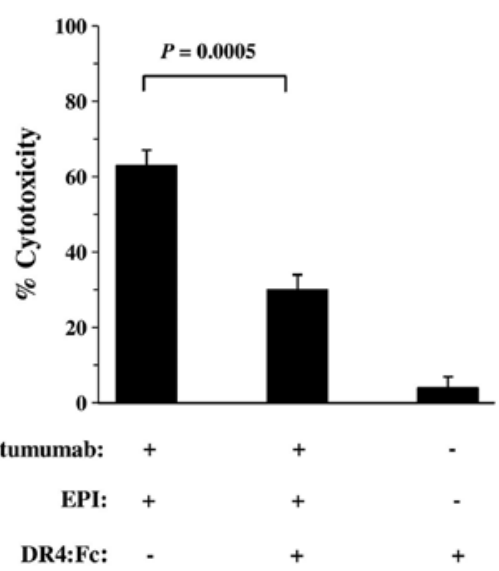

Figure 3. DR4-dependent synergistic cytotoxic effect of MAPA and EPI in bladder cancer cells. T24 cells were treated with $1 \mu \mathrm{g} / \mathrm{ml}$ EPI for variable times. Total RNA was extracted with TRIzol reagent and used for cDNA synthesis. (A) mRNA levels of DR4 were determined by real-time RT-PCR. (B) DR4 expression was monitored by western blot analysis after $1 \mu \mathrm{g} / \mathrm{ml}$ EPI treatment for 3-12 h. $\beta$-actin was used as the loading control. Cells were treated with $100 \mathrm{ng} / \mathrm{ml}$ MAPA plus $1 \mu \mathrm{g} / \mathrm{ml}$ EPI in the absence or presence of $1 \mu \mathrm{g} / \mathrm{ml}$ DR4:Fc chimeric protein. (C) Cytotoxicity was measured using the MTT assay. DR4, death receptor 4; MAPA, mapatumumab; EPI, epirubicin.

observed (Fig. 2A), when T24 cells were incubated with these two agents simultaneously. A similar effect was also observed in the 253J cells (Fig. 2B), yet the effect was not significant in the case of J82 cells (Fig. 2C). These results indicate that the 

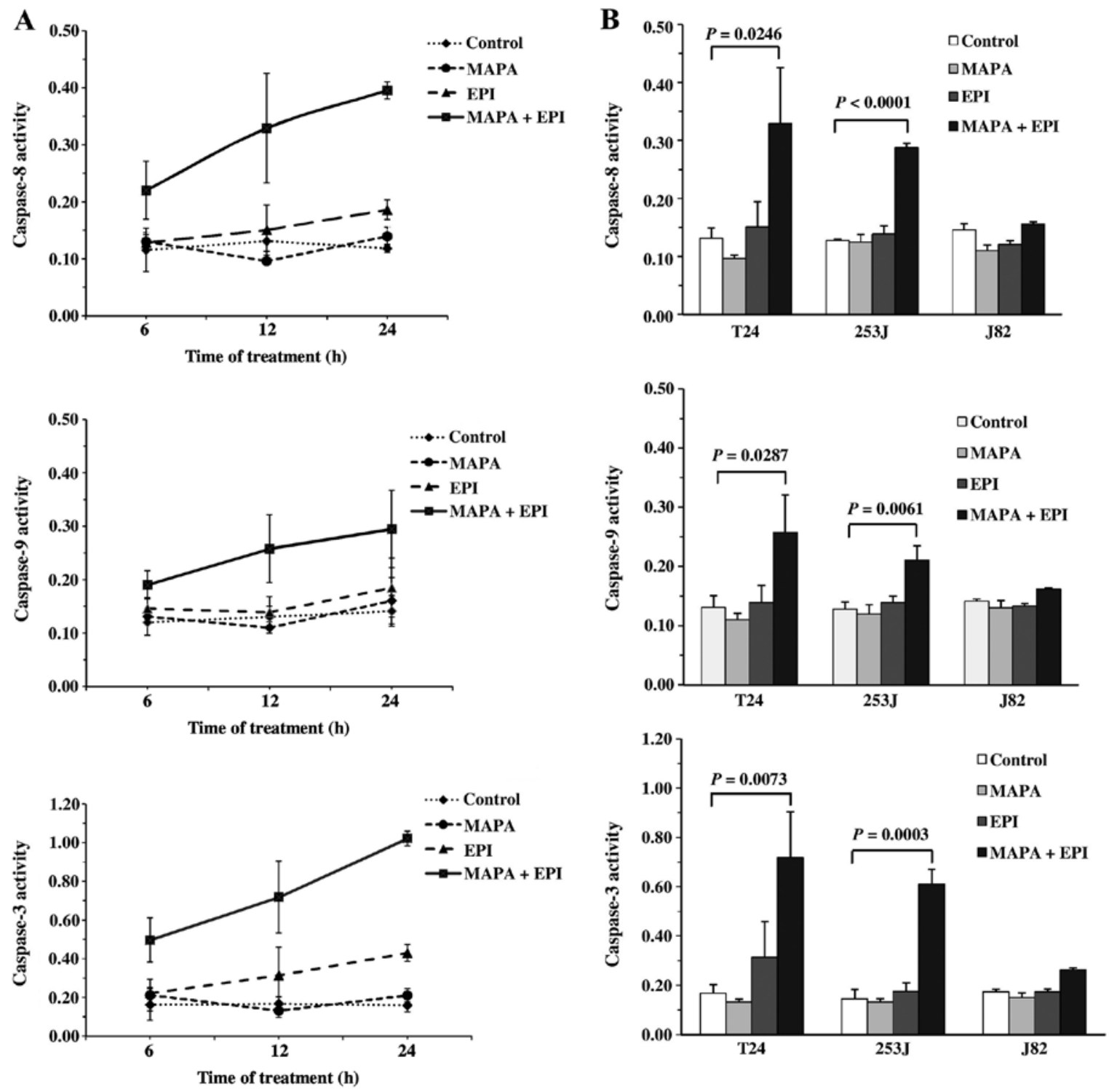

Figure 4. Caspase activation by MAPA and EPI in bladder cancer cells. T24 cells were treated for (A) $6-24 \mathrm{~h}$ or (B) $12 \mathrm{~h}$ with MAPA (100 ng/ml) alone, EPI $(1 \mu \mathrm{g} / \mathrm{ml})$ alone or a combination of the two agents. (A) Time course of caspase activation in T24 cells. (B) Comparison of caspase activities in T24, 253J and J82 cells. Activities of caspase- $8,-9$ and -3 were measured by a quantitative colorimetric assay. MAPA, mapatumumab; EPI, epirubicin.

combined cytotoxicity and the level of apoptosis were consistent in the bladder cancer cells.

Synergistic cytotoxicity of mapatumumab and EPI is DR4-dependent. It has been reported that cytotoxic drugs increase the expression of the TRAIL receptor in cancer cells $(24,25)$. To ascertain the mechanism underlying the interaction between mapatumumab and EPI, we examined whether EPI regulates the mRNA and protein levels of DR4 in bladder cancer cells by quantitative real-time RT-PCR and western blot analysis, respectively. The examination revealed that EPI significantly increased the DR4 expression in the T24 cells at the mRNA (Fig. 3A) and protein levels (Fig. 3B) in a time-dependent manner.

We further analyzed the molecular mechanism of the synergistic cytotoxicity of mapatumab and EPI using a human recombinant DR4:Fc chimeric protein which has a dominantnegative function against DR4. Cells were incubated with
$100 \mathrm{ng} / \mathrm{ml}$ mapatumumab plus $1 \mu \mathrm{g} / \mathrm{ml}$ EPI in the absence or presence of $1 \mu \mathrm{g} / \mathrm{ml}$ DR4:Fc chimeric protein. As shown in Fig. 3C, the synergistic cytotoxicity was blocked significantly by DR4:Fc chimeric protein in the T24 cells. These results indicate that the synergistic cytotoxicity and levels of apoptosis of mapatumumab and EPI were DR4-dependent.

Functional activation of caspase-8, -9 and -3 following treatment with mapatumumab and EPI. In most biological systems, caspase activation plays an important role in executing apoptosis (26). Activation of caspase- 8 is initially led by the TNF receptor family including TRAIL-R1, resulting in the initiation of a cascade in which other caspases such as caspase-3 and -9 are activated. This ultimately causes the irreversible commitment of cells to undergo apoptosis $(11,13)$. Treatment of T24 with the combination of mapatumumab and EPI resulted in significant activation of caspase-8, -9 and -3 , although EPI alone slightly activated caspase- 8 and -3 (Fig. 4A). In contrast, 
mapatumumab alone did not activate casapse- $8,-9$ or -3 . Caspase activation was observed when the treatment time of T24 cells with mapatumumab and EPI was shortened from 24 to $6 \mathrm{~h}$ (Fig. 4A). We also examined caspase activation using 253J and J82 cells, and observed that the 253J cells exhibited a similar effect, whereas the $\mathrm{J} 82$ cells showed a poor effect (Fig. 4B).

\section{Discussion}

Although human agonistic antibodies to TRAIL receptors are currently in clinical trials for the treatment of cancer patients, resistance of cancer cells to apoptosis is one of the major hurdles in the effective application of these molecular target therapeutic drugs. Thus, agents that can overcome resistance are urgently needed (18-20,27). In the present study, we demonstrated that the anthracycline EPI, in combination with mapatumumab, enhanced apoptosis-inducing activity in human bladder cancer cells T24, KU7, 253J and RT112. The observed activation of caspase- $8,-9$ and -3 in our experiments suggests that the combination of mapatumumab and EPI potentiates both the extrinsic and intrinsic pathways of apoptosis. A relatively low concentration of each agent was required, thus minimizing drug toxicity and maximizing the therapeutic potential in vivo. In addition, a synergistic effect was also observed with mapatumumab in combination with other anthracyline derivatives such as THP. These data suggest that combination treatment using mapatumumab and anthracyclines is promising from a clinical perspective.

Cell surface expression of DR4 or DR5 is essential for TRAIL-induced apoptosis, although tumor cells expressing these death receptors are not always sensitive to TRAIL due to intracellular mechanisms (28). It was reported that the efficacy of TRAIL correlates with the cell surface levels of DR4 and/or DR5 in leukemia cells (29). However, some studies showed that TRAIL receptor expression does not correspond to the synergy of TRAIL and chemotherapeutic drugs in certain cell lines (30-33). The present study showed that EPI significantly upregulated DR4 expression in bladder cancer cells at both the mRNA and protein levels. Furthermore, the synergistic cytotoxicity of mapatumumab and EPI was significantly inhibited by DR4:Fc chimeric protein that had a dominant-negative function against DR4. These findings imply that mapatumumab and EPI synergistically induce cytotoxicity and apoptosis in bladder cancer cells through upregulation of DR4.

Caspases are critical protease mediators of apoptosis triggered by different stimuli including TRAIL $(9,34,35)$. In the present study, we found that in T24 and 253J cells treated with the combination of mapatumumab and EPI, the initiative caspases such as caspase-8, -9 and effective caspases including caspase- 3 were significantly activated. The strong activation of caspase- 8 in bladder cancer cells treated with the combination of mapatumamab and EPI may be the result of increased death-inducing signaling complex activity or secondary to activation by downstream caspases. These findings revealed that the activation of the extrinsic and intrinsic apoptotic pathways has an important role in synergistic cytotoxicity of mapatumumab and EPI in bladder cancer cells.

It was noted that the $\mathrm{J} 82$ cells exhibited no significant enhanced cytotoxicity and apoptosis after treatment using mapatumumab in combination with EPI, although the synergistic effect was achieved in most bladder cancer cells. In addition, neither caspase- $8,-9$ nor -3 was activated in the J82 cells treated with mapatumumab and EPI. These findings further indicate that caspases are critical in the enhancement of DR4-mediated apoptosis in most bladder cancer cells following treatment with EPI.

The chemotherapeutic drug resistance of bladder cancer cells remains a major obstacle to successful treatment, and thus more effective therapy is needed. The present study clearly demonstrated that mapatumumab and EPI had a synergistic cytotoxic effect in most bladder cancer cells at a relatively low concentration of EPI compared to a regular dose. The synergistic cytotoxicity of mapatumumab and EPI was realized through induction of apoptosis upon upregulating DR4 expression and activating the caspase cascade. These findings suggest that the treatment of bladder cancer using mapatumumab combined with EPI is promising in a potential clinical setting.

\section{References}

1. Griffiths TR; Action on Bladder Cancer: Current perspectives in bladder cancer management. Int J Clin Pract 67: 435-448, 2013.

2. Li Y, Jin X, Li J, Yu J, Sun X, Chu Y, Xu C, Li X, Wang X, Kakehi $Y$ and Wu X: Expression of TRAIL, DR4, and DR5 in bladder cancer: correlation with response to adjuvant therapy and implications of prognosis. Urology 79: 968.e7-968.e15, 2012.

3. Chen SY, Du LD and Zhang YH: Pilot study of intravesical instillation of two new generation anthracycline antibiotics in prevention of superficial bladder cancer recurrence. Chin Med J 23: 3422-3426, 2010.

4. Wu XX and Kakehi Y: Enhancement of lexatumumab-induced apoptosis in human solid cancer cells by cisplatin in caspasedependent manner. Clin Cancer Res 15: 2039-2047, 2009.

5. Walczak H, Miller RE, Ariail K, Gliniak B, Griffith TS, Kubin M, Chin W, Jones J, Woodward A, Le T, Smith C, Smolak P, Goodwin RG, Rauch CT, Schuh JC and Lynch DH: Tumoricidal activity of tumor necrosis factor-related apoptosisinducing ligand in vivo. Nat Med 5: 157-163, 1999.

6. Hao C, Song JH, Hsi B, Lewis J, Song DK, Petruk KC, Tyrrell DL and Kneteman NM: TRAIL inhibits tumor growth but is nontoxic to human hepatocytes in chimeric mice. Cancer Res 64: 8502-8506, 2004.

7. Pan G, O'Rourke K, Chinnaiyan AM, Gentz R, Ebner R, Ni J and Dixit VM: The receptor for the cytotoxic ligand TRAIL. Science 276: 111-113, 1997.

8. Pan G, Ni J, Wei YF, Yu G, Gentz R and Dixit VM: An antagonist decoy receptor and a death domain-containing receptor for TRAIL. Science 277: 815-818, 1997.

9. Ashkenazi A and Dixit VM: Death receptors: signaling and modulation. Science 281: 1305-1308, 1998.

10. Shimada O, Wu X, Jin X, Nouh MA, Fiscella M, Albert V, Matsuda T and Kakehi Y: Human agonistic antibody to tumor necrosis factor-related apoptosis-inducing ligand receptor 2 induces cytotoxicity and apoptosis in prostate cancer and bladder cancer cells. Urology 69: 395-401, 2007.

11. Chuntharapai A, Dodge K, Grimmer K, Schroeder K, Marsters SA, Koeppen H, Ashkenazi A and Kim KJ: Isotypedependent inhibition of tumor growth in vivo by monoclonal antibodies to death receptor 4. J Immunol 166: 4891-4898, 2001.

12. Ichikawa K, Liu W, Zhao L, Wang Z, Liu D, Ohtsuka T, Zhang H, Mountz JD, Koopman WJ, Kimberly RP and Zhou T: Tumoricidal activity of a novel anti-human DR5 monoclonal antibody without hepatocyte cytotoxicity. Nat Med 7: 954-960, 2001.

13. Ohtsuka T, Buchsbaum D, Oliver P, Makhija S, Kimberly R and Zhou T: Synergistic induction of tumor cell apoptosis by death receptor antibody and chemotherapy agent through JNK/p38 and mitochondrial death pathway. Oncogene 22: 2034-2044, 2003.

14. Jin X, Wu XX, Abdel-Muneem Nouh MA and Kakehi Y: Enhancement of death receptor 4 mediated apoptosis and cytotoxicity in renal cell carcinoma cells by subtoxic concentrations of doxorubicin. J Urol 177: 1894-1899, 2007. 
15. Zeng Y, Wu XX, Fiscella M, Shimada O, Humphreys R, Albert $V$ and Kakehi Y: Monoclonal antibody to tumor necrosis factor-related apoptosis-inducing ligand receptor 2 (TRAIL-R2) induces apoptosis in primary renal cell carcinoma cells in vitro and inhibits tumor growth in vivo. Int $\mathrm{J}$ Oncol 28 : 421-430, 2006.

16. Szliszka E, Mazur B, Zydowicz G, Czuba ZP and Krol W: TRAIL-induced apoptosis and expression of death receptor TRAIL-R1 and TRAIL-R2 in bladder cancer cells. Folia Histochem Cytobiol 47: 579-585, 2009.

17. Pukac L, Kanakaraj P, Humphreys R, Alderson R, Bloom M, Sung C, Riccobene T, Johnson R, Fiscella M, Mahoney A, Carrell J, Boyd E, Yao XT, Zhang L, Zhong L, von Kerczek A, Shepard L, Vaughan T, Edwards B, Dobson C, Salcedo T and Albert V: HGS-ETR1, a fully human TRAIL-receptor 1 monoclonal antibody, induces cell death in multiple tumour types in vitro and in vivo. Br J Cancer 92: 1430-1441, 2005.

18. Tolcher AW, Mita M, Meropol NJ, von Mehren M, Patnaik A, Padavic K, Hill M, Mays T, McCoy T, Fox NL, Halpern W, Corey A and Cohen RB: Phase I pharmacokinetic and biologic correlative study of mapatumumab, a fully human monoclonal antibody with agonist activity to tumor necrosis factor-related apoptosis-inducing ligand receptor-1. J Clin Oncol 25: 1390-1395, 2007.

19. Greco FA, Bonomi P, Crawford J, Kelly K, Oh Y, Halpern W, Lo L, Gallant G and Klein J: Phase 2 study of mapatumumab, a fully human agonistic monoclonal antibody which targets and activates the TRAIL receptor-1, in patients with advanced non-small cell lung cancer. Lung Cancer 61: 82-90, 2008.

20. Hotte SJ, Hirte HW, Chen EX, Siu LL, Le LH, Corey A Iacobucci A, MacLean M, Lo L, Fox NL and Oza AM: A phase 1 study of mapatumumab (fully human monoclonal antibody to TRAIL-R1) in patients with advanced solid malignancies. Clin Cancer Res 14: 3450-3455, 2008.

21. Motzer RJ, Bander NH and Nanus DM: Renal-cell carcinoma. N Engl J Med 335: 865-875, 1996.

22. Berenbaum MC: Synergy, additivism and antagonism in immunosuppression. A critical review. Clin Exp Immunol 28: 1-18, 1977.

23. Berenbaum MC: A method for testing for synergy with any number of agents. J Infect Dis 137: 122-130, 1978.

24. Gibson SB, Oyer R, Spalding AC, Anderson SM and Johnson GL: Increased expression of death receptors 4 and 5 synergizes the apoptosis response to combined treatment with etoposide and TRAIL. Mol Cell Biol 20: 205-212, 2000.

25. Wu XX, Jin XH, Zeng Y, El Hamed AM and Kakehi Y: Low concentrations of doxorubicin sensitizes human solid cancer cells to tumor necrosis factor-related apoptosis-inducing ligand (TRAIL)-receptor (R) 2-mediated apoptosis by inducing TRAIL-R2 expression. Cancer Sci 98: 1969-1976, 2007.
26. Green DR and Evan GI: A matter of life and death. Cancer Cell 1: 19-30, 2002.

27. von Pawel J, Harvey JH, Spigel DR, Dediu M, Reck M, Cebotaru CL, Humphreys RC, Gribbin MJ, Fox NL and Camidge DR: Phase II trial of mapatumumab, a fully human agonist monoclonal antibody to tumor necrosis factor-related apoptosis-inducing ligand receptor 1 (TRAIL-R1), in combination with paclitaxel and carboplatin in patients with advanced non-small-cell lung cancer. Clin Lung Cancer 15: 188.e2-196.e2, 2014.

28. Amantana A, London CA, Iversen PL and Devi GR: X-linked inhibitor of apoptosis protein inhibition induces apoptosis and enhances chemotherapy sensitivity in human prostate cancer cells. Mol Cancer Ther 3: 699-707, 2004.

29. Liu Q, Hilsenbeck S and Gazitt Y: Arsenic trioxide-induced apoptosis in myeloma cells: $p 53$-dependent $\mathrm{G}_{1}$ or $\mathrm{G}_{2} / \mathrm{M}$ cell cycle arrest, activation of caspase- 8 or caspase-9, and synergy with APO2/TRAIL. Blood 101: 4078-4087, 2003.

30. Galligan L, Longley DB, McEwan M, Wilson TR, McLaughlin K and Johnston PG: Chemotherapy and TRAIL-mediated colon cancer cell death: the roles of p53, TRAIL receptors, and c-FLIP. Mol Cancer Ther 4: 2026-2036, 2005.

31. Lacour S, Hammann A, Wotawa A, Corcos L, Solary E and Dimanche-Boitrel MT: Anticancer agents sensitize tumor cells to tumor necrosis factor-related apoptosis-inducing ligandmediated caspase- 8 activation and apoptosis. Cancer Res 61: 1645-1651, 2001.

32. Liu W, Bodle E, Chen JY, Gao M, Rosen GD and Broaddus VC: Tumor necrosis factor-related apoptosis-inducing ligand and chemotherapy cooperate to induce apoptosis in mesothelioma cell lines. Am J Respir Cell Mol Biol 25: 111-118, 2001.

33. Tsai WS, Yeow WS, Chua A, Reddy RM, Nguyen DM, Schrump DS and Nguyen DM: Enhancement of Apo2L/TRAILmediated cytotoxicity in esophageal cancer cells by cisplatin. Mol Cancer Ther 5: 2977-2990, 2006.

34. Derosier LC, Vickers SM, Zinn KR, Huang Z, Wang W, Grizzle WE, Sellers J, Stockard CR Jr, Zhou T, Oliver PG, Arnoletti P, Lobuglio AF and Buchsbaum DJ: TRA-8 anti-DR5 monoclonal antibody and gemcitabine induce apoptosis and inhibit radiologically validated orthotopic pancreatic tumor growth. Mol Cancer Ther 6: 3198-3207, 2007.

35. O'Kane HF, Watson CJ, Johnston SR, Petak I, Watson RW and Williamson KE: Targeting death receptors in bladder, prostate and renal cancer. J Urol 175: 432-438, 2006. 